\title{
Música y lengua de signos a cuatro voces: una experiencia educativa y musical para la inclusión
}

Music and sign language at four voices: an educational and musical experience for inclusion

Borja Juan Morera 592496@unizar.es

Dpto. Expresión Musical, Plástica y Corporal. Facultad de Educación Universidad de Zaragoza

Zaragoza, España

ORCID: https://orcid.org/0000-0002-5943-5012

\author{
Icíar Nadal García \\ iciarnad@uniza.es \\ Dpto. Expresión Musical, Plástica y Corporal. Facultad de Educación \\ Universidad de Zaragoza \\ Zaragoza, España \\ ORCID: https://orcid.org/0000-0003-1325-2373 \\ María Belén López Casanova \\ belocasa@unizar.es \\ Dpto. Expresión Musical, Plástica y Corporal. Facultad de Educación \\ Universidad de Zaragoza \\ Zaragoza, España \\ ORCID: https://orcid.org/0000-0001-9101-6478
}

doi: 10.7203/LEEME.45.16244

Recibido: 12-12-2019 Aceptado: 11-02-2020. Icíar Nadal García, Dpto. Expresión Musical, Plástica y Corporal. Facultad de Educación. Universidad de Zaragoza, c/Pedro Cerbuna 12, C.P. 50009, Zaragoza. España.

\section{Resumen}

El binomio lengua de signos y música está adquiriendo cada vez más presencia en nuestra sociedad gracias a los medios de comunicación, las redes sociales y, en especial, a YouTube. Existe un escaso número de investigaciones que traten el tema en profundidad. En este artículo, se presenta una investigación de corte cualitativo, a través de un estudio de caso sobre el Coro Inclusivo Cantatutti que signa "a voces" la música polifónica, para acercar a personas con y sin discapacidad auditiva a la compresión de este estilo musical. El objetivo principal de nuestra investigación ha consistido en conocer la incidencia que produce en el intérprete y en el espectador, con y sin discapacidad auditiva, la música polifónica signada a cuatro voces. Tras el análisis de los resultados obtenidos durante el proceso, se puede concluir que esta música amplía el acceso a la cultura a las personas sordas y refuerza el concepto de forma visual a personas sin discapacidad auditiva

Palabras clave: Inclusión; canto Coral; lengua de signos; música.

\section{Abstract}

The binomial sign language and music are gaining more and more presence in our society thanks to the media, social networks and especially YouTube. Only a small number of investigations that deal with the subject in depth. In this article, a qualitative research is presented, through a case study on the Cantatutti Inclusive Choir that signs polyphonic music, to bring people with and without hearing disabilities to the compression of this musical style. The main objective of our research has been to know the incidence that signed polyphonic music in four voices has in the interpreter and in the viewer with and without hearing impairment. After analyzing the results obtained during the process, we can conclude that polyphonic music for a signed choir extends access to culture for deaf people and reinforces the concept visually, for people without hearing impairment.

Key words: Inclusion; singing; sign language; music.

@ Borja Juan Morera, Icíar Nadal García y María Belén López Casanova. The content of this article is the sole responsibility of the authors. The Revista Electrónica de LEEME and Universitat de València are not liable for any legal actions that may arise involving the article's content. Revista Electrónica de LEEME - Lista Electrónica Europea de Música en la Educación-. http://ojs.uv.es/index/php/LEEME/index ISSN: 1575-9563. Editores: Universidad de Valencia y Jesús Tejada. Visibilidad de esta revista: SCOPUS, Emerging Sources Citation Index (Clarivate), EBSCO, CINDOC (CSIC), Citefactor, COPAC, Dialnet, DICE (CSIC), DOAJ, e-revistas (CSIC), EBSCO Premier, ERIH+, Gale Cengage Learning, IN-RECS, IRESIE, LATINDEX, MIAR, OCLC Worldcat, RESH, REDIB, RILM Core Journals, SUDOC, ULRICHS. Esta revista es de acceso libre mediante licencia Creative Commons 4.0 CC by. Política de archivado: etiqueta verde SHERPA-ROMEO. 


\section{Introducción}

Actualmente, existe una importante sensibilización sobre el acceso de la música a las personas sordas a través del signado tanto de canciones como de música instrumental (Cripps, Rosenblum y Small, 2016), haciendo de la música una práctica más inclusiva. En los últimos años, están apareciendo diferentes cantantes, agrupaciones y colectivos que trabajan para acercar la música a un público con y sin discapacidad auditiva.

Tras la búsqueda y análisis, en las principales bases de datos (Web of Science, Scopus, ProQuest) de investigaciones y experiencias que tratan el tema, se localizan muy pocos documentos en España relacionados con la materia, como podrá comprobarse a continuación. Sin embargo, se detectan algunos estudios que analizan este fenómeno, principalmente en EE.UU., debido a la trascendencia y popularidad que ha adquirido en los últimos años el signado de canciones a través de las redes sociales.

\subsection{Antecedentes en EE.UU. y España}

Las primeras incursiones en interpretación de canciones en lengua de signos se desarrollan en EE.UU. Según Cripps (2018), el primer registro de música signada aparece en el año 1902, en la película de cine mudo "Star Spangled Banner", donde una mujer sorda interpreta en lengua de signos el himno nacional estadounidense. Otro registro de canciones signadas se encuentra en un proyecto cinematográfico de la Asociación Nacional de Sordos de EE.UU., producido entre 1910 y 1920 (Bahan, 2006). Más tarde, en los años 30, se vuelven a localizar nuevas muestras en las películas del director de cine americano Charles Krauel, en donde aparecen algunas tomas de canciones signadas.

Los siguientes documentos emergen en los años 60, en el Teatro Nacional de Sordos, donde introducen dos canciones signadas: "Rescue at Sea" y "The Three Blind Mice". Y es a partir de 1990 cuando empiezan a surgir más ejemplos de canciones signadas (Cripps, 2018). No obstante, las interpretaciones de las canciones para lengua de signos americana (ASL) también se encontraba comúnmente en las iglesias y las realizaban intérpretes contratados y estudiantes de lengua de signos (Maler, 2013). Actualmente, en EE.UU. las personas que a través de la lengua de signos interpretan música para sordos se han convertido en verdaderas estrellas mediáticas, sobre todo, desde su aparición en las redes sociales. Son intérpretes de la música en la lengua de signos estadounidense (ASL), y su oficio implica no solo el dominio de ASL, sino también la empatía, la creatividad, la espontaneidad, el baile, etc. (Jones, 2017). Cripps y Lyonblum (2017), entienden la "música signada" como una forma única de espectáculo, aunque comparta elementos que son comunes a la música en general.

@ Borja Juan Morera, Icíar Nadal García y María Belén López Casanova. The content of this article is the sole responsibility of the authors. The Revista Electrónica de LEEME and Universitat de València are not liable for any legal actions that may arise involving the article's content. Revista Electrónica de LEEME - Lista Electrónica Europea de Música en la Educación-. http://ojs.uv.es/index/php/LEEME/index ISSN: 1575-9563. Editores: Universidad de Valencia y Jesús Tejada. Visibilidad de esta revista: SCOPUS, Emerging Sources Citation Index (Clarivate), EBSCO, CINDOC (CSIC), Citefactor, COPAC, Dialnet, DICE (CSIC), DOAJ, e-revistas (CSIC), EBSCO Premier, ERIH+, Gale Cengage Learning, IN-RECS, IRESIE, LATINDEX, MIAR, OCLC Worldcat, RESH, REDIB, RILM Core Journals, SUDOC, ULRICHS. Esta revista es de acceso libre mediante licencia Creative Commons 4.0 CC by. Política de archivado: etiqueta verde SHERPA-ROMEO. 


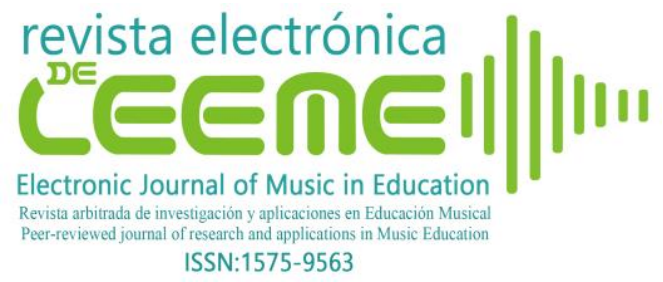

Borja Juan Morera, Icíar Nadal García, María Belén López Casanova Música y lengua de signos a cuatro voces, una experiencia educativa y musical para la inclusión (Revista Electrónica de LEEME) Número 45, pp. 35-52 https://ojs.uv.es/index.php/LEEME/index ISSN:1575-9563

En España, no se localizan documentos que acrediten cuándo comienza esta práctica. No obstante, en la actualidad algunos músicos y cantantes ofrecen conciertos acompañados de intérpretes de lengua de signos española (ILSE). Aunque ha sido una práctica habitual en la comunidad sorda, es actualmente cuando adquiere mayor visibilidad y difusión a través de las plataformas de redes sociales. Uno de los pioneros en introducir el uso de intérpretes de lengua de signos en España (LSE) fue el cantautor Tontxu Ipiña, que incorporó en 2008 a sus conciertos a Evelin Vega, intérprete en LSE (Valle, 2008). La cantante y compositora madrileña Laura Honrubia, con su grupo "Dale al aire", comenzó su utilización en el año 2009 (Ruiz Marull, 2017). Sin embargo, el ejemplo más mediático en utilizar la ILSE es el de la cantautora española Rozalén que, junto con la intérprete de lengua de signos Beatriz Romero, ofrecen conciertos en directo desde el año 2013 llegando así a un público más amplio, incluyendo a la comunidad sorda, haciendo que la música se pueda escuchar y sentir a través de la vista (García, 2016).

\subsection{Tipos de música signada}

La comunidad sorda se puede comunicar de dos formas: utilizando la lengua de signos o la Comunicación Bimodal. La lengua natural de las personas sordas es la lengua de signos, que es una lengua como el inglés, francés, etc., sólo que gestual. Tiene su propia estructura, gramática y sintaxis, y no es universal: varía de un país a otro y dentro de España tiene distintas acepciones, es decir, que los signos pueden variar de una comunidad autónoma a otra (Valdés, 2013). La lengua de signos tiene su propia estructura y prioriza las palabras claves que dan la información a las personas sordas sin tener en cuenta la estructura del lenguaje oral.

En cuanto al sistema bimodal (Ferraro, 2018), consiste en utilizar los signos simultáneamente con la lengua oral y fue introducido por Schlesinger (1978). Valdés (2013) señala que:

"La comunicación bimodal, es un sistema creado a medio camino entre la lengua oral y la lengua de signos. El vocabulario es el de la lengua de signos y la estructura que se sigue es la de la lengua oral, para los oyentes es más fácil de aprender."'

En la cultura sorda hay dos tipos de canciones signadas (Bahan, 2006; Listman, Loeffler y Timm 2018): las canciones traducidas y las canciones signadas de percusión. Esta última categoría requiere la organización de signos a tempo de la música. A estas dos clasificaciones, habría que añadir el signado de música instrumental, en la que juega un papel indispensable la expresión corporal, facial y los planos donde se realiza el signado para ubicar los diferentes parámetros de la música.

\footnotetext{
${ }^{1}$ Recuperado de http://valdescarmen.blogspot.com/2013/07/la-lengua-de-signos-y-la-comunicacion.html
}

@ Borja Juan Morera, Icíar Nadal García y María Belén López Casanova. The content of this article is the sole responsibility of the authors. The Revista Electrónica de LEEME and Universitat de València are not liable for any legal actions that may arise involving the article's content. Revista Electrónica de LEEME - Lista Electrónica Europea de Música en la Educación-. http://ojs.uv.es/index/php/LEEME/index ISSN: 1575-9563. Editores: Universidad de Valencia y Jesús Tejada. Visibilidad de esta revista: SCOPUS, Emerging Sources Citation Index (Clarivate), EBSCO, CINDOC (CSIC), Citefactor, COPAC, Dialnet, DICE (CSIC), DOAJ, e-revistas (CSIC), EBSCO Premier, ERIH+, Gale Cengage Learning, IN-RECS, IRESIE, LATINDEX, MIAR, OCLC Worldcat, RESH, REDIB, RILM Core Journals, SUDOC, ULRICHS. Esta revista es de acceso libre mediante licencia Creative Commons 4.0 CC by. Política de archivado: etiqueta verde SHERPA-ROMEO. 


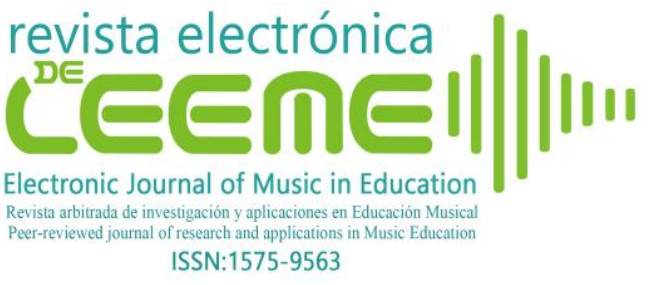

Borja Juan Morera, Icíar Nadal García, María Belén López Casanova Música y lengua de signos a cuatro voces, una experiencia educativa y musical para la inclusión. (Revista Electrónica de LEEME) Número 45, pp. 35-52 https://ojs.uv.es/index.php/LEEME/inde

Según Serna y Piñero (2017, p.71), la interpretación de canciones en lengua de signos española (ILSEC) "se ha conformado como una nueva modalidad dentro del campo de la interpretación". Se trata de una nueva forma de escuchar y hacer música donde no sólo participa el fenómeno sonoro, sino que la expresión corporal, la mirada y la puesta en escena, son aspectos claves (Bahan, 2006; Kaneko, 2011; Straus, 2011; Maler, 2013; Cook, 2017). Es decir, los movimientos de las manos no sólo traducen el texto, sino que también interpretan los sentimientos que la música produce: consiste en escuchar la música con la mirada. Recientemente, han surgido algunos estudios que consideran estas interpretaciones como un fenómeno multimodal (Maler, 2013; Cripps, 2018; Peñalba, Moriyón y Luque, 2018), que va más allá de lo sonoro y que permite hacer accesible la música a personas sordas, sin olvidar la importancia de su grado de diversidad funcional a nivel auditivo, antecedentes educativos, culturales, etc. Además, los intérpretes transmiten un mensaje, una intención y un sentimiento que llega de forma directa al espectador, se convierten en artistas.

Esta forma de interpretar la música cumple funciones tanto comunicativas como cognitivas, tal como afirman Thompson, Cotnoir-Bichelman, McKerchar, Tate y Dancho (2007) en sus investigaciones. El signado de canciones no se debe quedar en una mera traducción del texto, ya que tendría el mismo interés que la traducción de un texto literario. Es necesaria la representación a través del movimiento rítmico corporal para llegar a las emociones y sentimientos que provoca la música. El factor expresivo debe ser el más intenso (Buchholz, 2018; Silvestri, Ehrenberg, Dick y Shim, 2018).

A pesar de llevar un considerable tiempo en uso la utilización de la lengua de signos para acompañar o interpretar música, siempre se aplica a canciones monofónicas, es decir, de una sola voz. Pero no existen documentos escritos que planteen la posibilidad de signar todas las voces de la polifonía. Sin embargo, el proyecto de Coro Inclusivo Cantatutti de la Universidad de Zaragoza lleva incluyendo entre sus experiencias, desde octubre de 2017, el signado de canciones a dos, tres y cuatro voces para coro mixto. A través de su forma de expresión multimodal (voz, lengua de signos y expresión corporal), Cantatutti puede llegar a un mayor número de público con y sin discapacidad auditiva, experimentando nuevas experiencias y haciendo más accesible a personas sordas y oyentes esta parte de la cultura.

Esta experiencia, unida al interés suscitado en la comunidad sorda, lleva a plantear una línea de investigación que, bebiendo de las fuentes donde se asientan los principios del signado musical para personas con discapacidad auditiva, pretende ir más allá y abrir una nueva vía en el signado de la polifonía para la apreciación de la estética, la complejidad y la belleza de la música a varias voces. Por tanto, el principal propósito del presente estudio consiste en detectar de qué manera incide la interpretación de la música signada tanto en el intérprete como en el espectador con y sin diversidad funcional, desarrollando una función más inclusiva.

@ Borja Juan Morera, Icíar Nadal García y María Belén López Casanova. The content of this article is the sole responsibility of the authors. The Revista Electrónica de LEEME and Universitat de València are not liable for any legal actions that may arise involving the article's content. Revista Electrónica de LEEME - Lista Electrónica Europea de Música en la Educación-. http://ojs.uv.es/index/php/LEEME/index ISSN: 1575-9563. Editores: Universidad de Valencia y Jesús Tejada. Visibilidad de esta revista: SCOPUS, Emerging Sources Citation Index (Clarivate), EBSCO, CINDOC (CSIC), Citefactor, COPAC, Dialnet, DICE (CSIC), DOAJ, e-revistas (CSIC), EBSCO Premier, ERIH+, Gale Cengage Learning, IN-RECS, IRESIE, LATINDEX, MIAR, OCLC Worldcat, RESH, REDIB, RILM Core Journals, SUDOC, ULRICHS. Esta revista es de acceso libre mediante licencia Creative Commons 4.0 CC by. Política de archivado: etiqueta verde SHERPA-ROMEO. 


\section{Método}

Tras la experiencia desarrollada con el coro Cantatutti, se plantea como objetivo principal conocer la incidencia e impacto significativo que produce la música polifónica signada a cuatro voces en el intérprete y en el espectador con y sin discapacidad auditiva. Se parte de la hipótesis de que el signado de la música polifónica repercute de forma directa en aspectos como la mejora de la interpretación, recepción y comprensión, transmisión del mensaje musical y extramusical de las canciones, así como que establece un vínculo expresivo entre la música y el gesto signado. Y esto incide de manera significativa tanto en la comunidad oyente como no oyente, como se constata en el presente estudio.

Se ha optado por profundizar en la comprensión del fenómeno planteado y se diseña un estudio de caso, de corte cualitativo, sobre el Coro Cantatutti. Pero, antes incluso de elegir dicho método, se ha realizado una revisión bibliográfica que tenía por objetivo acercarse al objeto de estudio y averiguar con qué técnica se podía hacer una aportación mayor al estado de la cuestión. Para acercarse a las principales tendencias en interpretación musical con lengua de signos, se ha realizado una búsqueda bibliográfica en las principales bases de datos con contenidos académicos relacionados: Web of Science, Scopus, ProQuest, y el buscador digital Google Scholar, revistas especializadas en lengua de signos, etc. Por otro lado, se han realizado búsquedas en YouTube de música signada y páginas Web de centros educativos especializados, principalmente. Esto ha permitido plasmar algunas de las prácticas más comunes utilizadas por los miembros de la cultura sorda para la interpretación musical, clasificándolas a partir de una bibliografía que corresponde, casi en exclusiva, a la comunidad científico-educativa anglosajona.

La revisión bibliográfica también ha permitido el acercamiento a los trabajos previos realizados por otros autores, así como la familiarización con la terminología específica. Ha servido además para identificar las metodologías concretas y los aportes al conocimiento que, desde nuestra experiencia con el Coro Cantatutti de la Universidad de Zaragoza, podía hacerse. Por tanto, esta revisión bibliográfica conlleva una metodología de estudio de caso. Para Arnal, Del Rincón y Latorre (1994), el estudio de caso debe ir encaminado a la toma de decisiones, centrando su interés y poder estratégico en un evento (una experiencia), para descubrir una posible aplicabilidad a situaciones naturales. Describir un caso en concreto facilita su comprensión, además se ve favorecida por los investigadores en el campo y su implicación facilita una descripción adecuada de la realidad que se presenta (Imbernón, 2002). De esta manera, se realiza una descripción basada en el propio trabajo en el Coro Cantatutti, reflexionando desde la propia experiencia con el fin de aportar nuevos conocimientos al área en la que se esté investigando. Así, el diseño propuesto se planteó con las siguientes fases:

@ Borja Juan Morera, Icíar Nadal García y María Belén López Casanova. The content of this article is the sole responsibility of the authors. The Revista Electrónica de LEEME and Universitat de València are not liable for any legal actions that may arise involving the article's content. Revista Electrónica de LEEME - Lista Electrónica Europea de Música en la Educación-. http://ojs.uv.es/index/php/LEEME/index ISSN: 1575-9563. Editores: Universidad de Valencia y Jesús Tejada. Visibilidad de esta revista: SCOPUS, Emerging Sources Citation Index (Clarivate), EBSCO, CINDOC (CSIC), Citefactor, COPAC, Dialnet, DICE (CSIC), DOAJ, e-revistas (CSIC), EBSCO Premier, ERIH+, Gale Cengage Learning, IN-RECS, IRESIE, LATINDEX, MIAR, OCLC Worldcat, RESH, REDIB, RILM Core Journals, SUDOC, ULRICHS. Esta revista es de acceso libre mediante licencia Creative Commons 4.0 CC by. Política de archivado: etiqueta verde SHERPA-ROMEO. 
- Recogida de información: observación participante y recogida de datos a través del cuaderno de campo, realización de entrevistas semiestructuradas y creación de un grupo de discusión.

- Verificación y confirmación de los datos: el análisis de los datos recogidos y su triangulación se ha llevado a cabo con el software NVivo. Esta herramienta se dirige a la investigación con métodos cualitativos y mixtos. Sirve para organizar, analizar y encontrar perspectivas en datos no estructurados o cualitativos, como: entrevistas, respuestas de encuestas con preguntas abiertas, contenido de las redes sociales, etc.

- Interpretación de la información. Discusión y conclusiones.

\subsection{Contexto}

El estudio de caso se contextualiza en el coro Cantatutti de la Universidad de Zaragoza. Lo conforman estudiantes con y sin diversidad funcional, personal docente e investigador, personal de administración y servicios, y ciudadanos en general. Está integrado por 80 componentes, de los cuales más de la mitad $(64,2 \%)$ son estudiantes de la Universidad de Zaragoza y el resto pertenecen a los otros colectivos mencionados. En el momento que se realiza la investigación, el 64\% son mujeres y el 36\% hombres. El 35\% de los participantes presenta algún tipo de diversidad funcional (visual, auditiva, física o psíquica). La edad media se sitúa entre los 18 y 25 años.

El $68 \%$ de los coralistas participa por primera vez en un coro. Solo el $10 \%$ tiene estudios musicales reglados, el $19 \%$ no tiene ningún conocimiento musical y el resto, los adquiridos en Educación Primaria o de forma amateur y autodidacta.

Es importante destacar que es un coro que canta con la voz y con lengua de signos española (LSE). El signado lo realizan todos los componentes del coro, con y sin diversidad funcional (a excepción de aquellas personas con diversidad funcional visual).

\subsection{Muestra}

La muestra de sujetos de los que se extraen los datos para el presente estudio de caso se puede clasificar en tres grupos: los participantes en las entrevistas semiestructuradas (8), los participantes en el grupo de discusión interno del coro Cantatutti (40), y los participantes de las sesiones observadas con la Asociación ASZA (35) y alumnado del Colegio de La Purísima de Zaragoza (18).

@ Borja Juan Morera, Icíar Nadal García y María Belén López Casanova. The content of this article is the sole responsibility of the authors. The Revista Electrónica de LEEME and Universitat de València are not liable for any legal actions that may arise involving the article's content. Revista Electrónica de LEEME - Lista Electrónica Europea de Música en la Educación-. http://ojs.uv.es/index/php/LEEME/index ISSN: 1575-9563. Editores: Universidad de Valencia y Jesús Tejada. Visibilidad de esta revista: SCOPUS, Emerging Sources Citation Index (Clarivate), EBSCO, CINDOC (CSIC), Citefactor, COPAC, Dialnet, DICE (CSIC), DOAJ, e-revistas (CSIC), EBSCO Premier, ERIH+, Gale Cengage Learning, IN-RECS, IRESIE, LATINDEX, MIAR, OCLC Worldcat, RESH, REDIB, RILM Core Journals, SUDOC, ULRICHS. Esta revista es de acceso libre mediante licencia Creative Commons 4.0 CC by. Política de archivado: etiqueta verde SHERPA-ROMEO. 
En cuanto a las entrevistas semiestructuradas:

1. El perfil de los informantes participantes (I.P.) es:

- I.P.1: contralto, sin conocimientos musicales, participa en el coro desde hace dos años y tres meses. Ansiedad y otras afecciones psíquicas.

- I.P.2: soprano, con conocimientos musicales, participa en el coro desde hace dos años y tres meses.

- I.P.3: soprano sin conocimientos musicales, participa en el coro desde hace dos años y tres meses.

- I.P.4: tenor, sin conocimientos musicales, participa en el coro desde hace dos años y tres meses. Asperger, con una discapacidad de $33 \%$.

2. El perfil de los informantes externos (I.E.) es:

- I.E.1: hombre sin conocimientos musicales. Trabajador de banca.

- I.E.2: hombre sin conocimientos musicales. Trabajador del sector sanitario.

-I.E.3: mujer con conocimientos musicales. Maestra de música y especialista en expresión corporal.

- I.E.4: mujer. Discapacidad auditiva total. Maestra en colegio de estudiantes sordos.

El segundo contexto es el referido al grupo de discusión, constituido por 40 componentes voluntarios del coro Cantatutti, con y sin diversidad funcional. Y, en cuanto al tercer contexto, el referido a los grupos de las sesiones observadas añade a la muestra los siguientes colectivos:

- Coro Cantatutti y Asociación ASZA (Agrupación de Personas Sordas de Zaragoza y Aragón). En esta muestra participaron 35 sordos con una media de edad de 45 años.

- Coro Cantatutti y 18 estudiantes sordos de entre 8 y 12 años del Colegio La Purísima para estudiantes sordos de Zaragoza y del Centre Surdité Langage Massy de París.

- Coro Cantatutti en sus ensayos.

\subsection{Instrumentos}

\subsubsection{Instrumentos de recogida de datos}

Para llevar a cabo el estudio de caso y, dependiendo del tipo de estrategia utilizada, se han aplicado diferentes técnicas para el proceso y registro de los datos. Por un lado, a través de la observación participante, el cuaderno de campo ha servido para anotar y recoger la información de forma estructurada durante los ensayos y sesiones del coro. Por otro lado, se han confeccionado unas entrevistas semiestructuradas donde se tiene en cuenta los pasos descritos por Cohen y Manion (1990). El tipo de preguntas que se plantean son abiertas por definición,

@ Borja Juan Morera, Icíar Nadal García y María Belén López Casanova. The content of this article is the sole responsibility of the authors. The Revista Electrónica de LEEME and Universitat de València are not liable for any legal actions that may arise involving the article's content. Revista Electrónica de LEEME - Lista Electrónica Europea de Música en la Educación-. http://ojs.uv.es/index/php/LEEME/index ISSN: 1575-9563. Editores: Universidad de Valencia y Jesús Tejada. Visibilidad de esta revista: SCOPUS, Emerging Sources Citation Index (Clarivate), EBSCO, CINDOC (CSIC), Citefactor, COPAC, Dialnet, DICE (CSIC), DOAJ, e-revistas (CSIC), EBSCO Premier, ERIH+, Gale Cengage Learning, IN-RECS, IRESIE, LATINDEX, MIAR, OCLC Worldcat, RESH, REDIB, RILM Core Journals, SUDOC, ULRICHS. Esta revista es de acceso libre mediante licencia Creative Commons 4.0 CC by. Política de archivado: etiqueta verde SHERPA-ROMEO. 


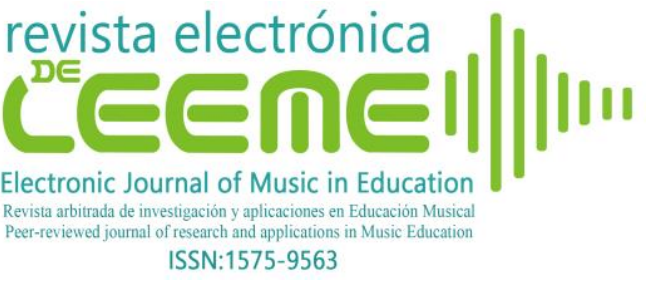

Borja Juan Morera, Icíar Nadal García, María Belén López Casanova Música y lengua de signos a cuatro voces, una experiencia educativa y musical para la inclusión. (Revista Electrónica de LEEME) Número 45, pp. 35-52 https://ojs.uv.es/index.php/LEEME/index ISSN:1575-9563

sin categorías de respuesta preestablecidas. El sistema de codificación ha sido flexible y abierto a cambios en todo momento (Ruiz Olabuénaga, 1999).

Las entrevistas las respondieron informantes externos (público) e informantes participantes (coralistas). Para las entrevistas de los informantes externos, se ha recurrido al visionado de diferentes grabaciones de canciones signadas a cuatro voces por el Coro Cantatutti. Las entrevistas han sido registradas mediante una grabadora y transcritas a ordenador gracias al software de reconocimiento de voz de la Suite Google y el posterior tratamiento del texto reconocido.

Finalmente, se ha creado un grupo de discusión en el que han participado componentes del coro después de realizar una actuación. En palabras de Krueger (1991, p.25), "un grupo de discusión puede ser definido como una conversación planeada, diseñada para obtener información de un área definida de interés, en un ambiente permisivo no-directivo".

\subsubsection{Instrumentos de análisis de datos}

Para el análisis de datos se ha realizado una codificación, categorización e interpretación del texto a partir del software Nvivo, que facilita notablemente la codificación y análisis de las transcripciones de documentos, permitiendo almacenar, organizar y obtener informes resumidos de los datos más significativos que emergen del análisis, así como combinar una doble dimensión en éste, integrando una perspectiva narrativa y otra más analítica.

\subsection{Procedimiento}

\subsubsection{Procedimiento de recogida de datos}

Hay que tener en cuenta que la actividad investigadora en torno a este coro lleva desarrollándose de forma continua desde octubre de 2017. Desde este momento, se registran datos a través de vídeos y cuadernos de observación y, también, se han utilizado otros instrumentos para diversas investigaciones paralelas. Por ello, en primer lugar, se han seleccionado varias sesiones que habían sido registradas y que consideramos representativas o de utilidad para analizar e intentar comprobar si se cumple la hipótesis ligada al objetivo principal de esta investigación.

De esta forma, la información utilizada, registrada a través de vídeos y cuadernos de campo, ha sido: la relativa al concierto de navidad ofrecido en la sede de ASZA donde se ofreció un concierto con música signada a un público, en su totalidad, sordo, y con el que pudimos intercambiar impresiones de la actividad; una sesión de trabajo y muestra con música signada realizada con una clase de Educación Primaria del Colegio "La Purísima" para estudiantes sordos de Zaragoza y sus invitados de intercambio del colegio de sordos "Centre Surdité Langage Massy" de París, y una pequeña recopilación de 3 sesiones espaciadas cada una de ellas en 6 meses, desde la actualidad hacia atrás, que recogen la actividad diaria del coro

@ Borja Juan Morera, Icíar Nadal García y María Belén López Casanova. The content of this article is the sole responsibility of the authors. The Revista Electrónica de LEEME and Universitat de València are not liable for any legal actions that may arise involving the article's content. Revista Electrónica de LEEME - Lista Electrónica Europea de Música en la Educación-. http://ojs.uv.es/index/php/LEEME/index ISSN: 1575-9563. Editores: Universidad de Valencia y Jesús Tejada. Visibilidad de esta revista: SCOPUS, Emerging Sources Citation Index (Clarivate), EBSCO, CINDOC (CSIC), Citefactor, COPAC, Dialnet, DICE (CSIC), DOAJ, e-revistas (CSIC), EBSCO Premier, ERIH+, Gale Cengage Learning, IN-RECS, IRESIE, LATINDEX, MIAR, OCLC Worldcat, RESH, REDIB, RILM Core Journals, SUDOC, ULRICHS. Esta revista es de acceso libre mediante licencia Creative Commons 4.0 CC by. Política de archivado: etiqueta verde SHERPA-ROMEO. 


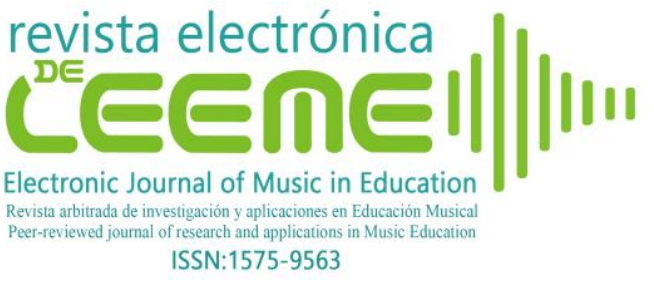

en su rutina de ensayo. Estas experiencias fueron registradas en vídeo y en anotaciones de cuadernos de campo por parte del equipo investigador implicado mientras tenía lugar la actividad.

En segundo lugar, se han realizado entrevistas semiestructuradas a algunos miembros del coro y espectadores del producto musical. Los informantes no han sido seleccionados al azar, sino que se ha pretendido tener la máxima representatividad atendiendo a las diferentes características y perfiles en cuanto a diversidad funcional y conocimientos musicales. Esta característica para la selección se considera tanto en los informantes internos como externos. La muestra se orienta a la selección de aquellas unidades y dimensiones que garantizan mejor la calidad (riqueza) de la información (Ruiz Olabuénaga, 1999). Las preguntas planteadas para las entrevistas han sido validadas por tres jueces expertos (especialista en música y antropología, especialista en Lengua de Signos Española y especialista en música para sordos). Las consideraciones aportadas por los expertos se tomaron en cuenta para la elaboración de la entrevista final. Las entrevistas tuvieron lugar en las instalaciones de la Universidad de Zaragoza, estando presentes los tres investigadores y haciendo uso de una aplicación móvil para grabar el audio y las herramientas de transcripción de la voz en tiempo real de la Suite de Google. A cada entrevistado se le dedicó media hora, explicándoles previamente las preguntas para que pudieran contestarlas con la mayor precisión y profundidad posible.

Por último, tras una de las actuaciones realizadas por el coro en noviembre de 2019, se planteó un grupo de discusión, formado por los asistentes al ensayo siguiente a la actuación para recoger las impresiones respecto a ciertos aspectos relacionados con este estudio y su actividad y, de esta manera, abrir la participación y riqueza de opiniones trianguladas en el estudio. El grupo de discusión tuvo una duración de 45 minutos y pudieron intervenir voluntariamente aquellos miembros que quisieron, sin límite de comentarios ni aportaciones. La información fue registrada en ese mismo momento por el equipo investigador en el cuaderno de campo.

\subsubsection{Procedimiento de análisis de los datos}

El análisis de los datos recogidos y su triangulación se ha llevado a cabo con el software NVivo. Después de introducir todos los documentos correspondientes a las entrevistas con 8 informantes, las anotaciones del cuaderno del investigador relativas a 3 sesiones representativas y las intervenciones derivadas del grupo de discusión planteado, ha surgido la siguiente jerarquía categorial:

1. Transmisión del mensaje:

- Transmite el mensaje.

- No transmite el mensaje.

2. Interpretación:

- Mejora la interpretación.

- Dificulta la interpretación.

@ Borja Juan Morera, Icíar Nadal García y María Belén López Casanova. The content of this article is the sole responsibility of the authors. The Revista Electrónica de LEEME and Universitat de València are not liable for any legal actions that may arise involving the article's content. Revista Electrónica de LEEME - Lista Electrónica Europea de Música en la Educación-. http://ojs.uv.es/index/php/LEEME/index ISSN: 1575-9563. Editores: Universidad de Valencia y Jesús Tejada. Visibilidad de esta revista: SCOPUS, Emerging Sources Citation Index (Clarivate), EBSCO, CINDOC (CSIC), Citefactor, COPAC, Dialnet, DICE (CSIC), DOAJ, e-revistas (CSIC), EBSCO Premier, ERIH+, Gale Cengage Learning, IN-RECS, IRESIE, LATINDEX, MIAR, OCLC Worldcat, RESH, REDIB, RILM Core Journals, SUDOC, ULRICHS. Esta revista es de acceso libre mediante licencia Creative Commons 4.0 CC by. Política de archivado: etiqueta verde SHERPA-ROMEO. 
3. Relación entre música y gesto:

- Vinculación entre música y gesto.

- No vinculación entre música y gesto.

4. Percepción y comprensión:

- Mejora la percepción y comprensión.

- No mejora la percepción y comprensión.

5. Dimensión emocional:

- Desarrolla la conciencia-expresión emocional.

- No desarrolla la conciencia-expresión emocional.

6. Conciencia inclusiva:

- Conciencia de contribución.

- No conciencia de contribución.

7. Valores y aptitudes extra-musicales:

- Desarrollo de valores extra-musicales.

- No desarrollo de valores extra-musicales.

Para dotar al análisis de un mayor rigor y fiabilidad, se ha categorizado y codificado la información de manera independiente por los tres investigadores, comparándola y poniéndola en común después para obtener la versión final de la misma de manera consensuada.

La transmisión del mensaje, la interpretación, la percepción o la relación entre música y gesto eran, a priori, las categorías planteadas por los investigadores como ejes de la investigación. Sin embargo, con el desarrollo de la investigación, que parte de una metodología abierta, que intenta comprender el entorno natural donde se desarrolla el fenómeno, emergieron otras categorías, ligadas a las dimensiones emocional, extramusical o inclusiva. Esto abre horizonte hacia nuevas ramificaciones futuras.

\section{Resultados}

Se presenta el mapa jerárquico obtenido de la triangulación de todos los instrumentos utilizados (Figura 1). En él podemos observar cómo existen cuatro elementos principales sobre los que gira la información obtenida, así como los tres emergentes ya comentados. Se observa que, con gran amplitud, los nodos o categorías que hacen referencia a la mejora de la interpretación, recepción, transmisión del mensaje o vinculación de música y gesto superan a sus opuestos, confirmando las hipótesis vinculadas al objetivo de nuestra investigación.

@ Borja Juan Morera, Icíar Nadal García y María Belén López Casanova. The content of this article is the sole responsibility of the authors. The Revista Electrónica de LEEME and Universitat de València are not liable for any legal actions that may arise involving the article's content. Revista Electrónica de LEEME - Lista Electrónica Europea de Música en la Educación-. http://ojs.uv.es/index/php/LEEME/index ISSN: 1575-9563. Editores: Universidad de Valencia y Jesús Tejada. Visibilidad de esta revista: SCOPUS, Emerging Sources Citation Index (Clarivate), EBSCO, CINDOC (CSIC), Citefactor, COPAC, Dialnet, DICE (CSIC), DOAJ, e-revistas (CSIC), EBSCO Premier, ERIH+, Gale Cengage Learning, IN-RECS, IRESIE, LATINDEX, MIAR, OCLC Worldcat, RESH, REDIB, RILM Core Journals, SUDOC, ULRICHS. Esta revista es de acceso libre mediante licencia Creative Commons 4.0 CC by. Política de archivado: etiqueta verde SHERPA-ROMEO. 


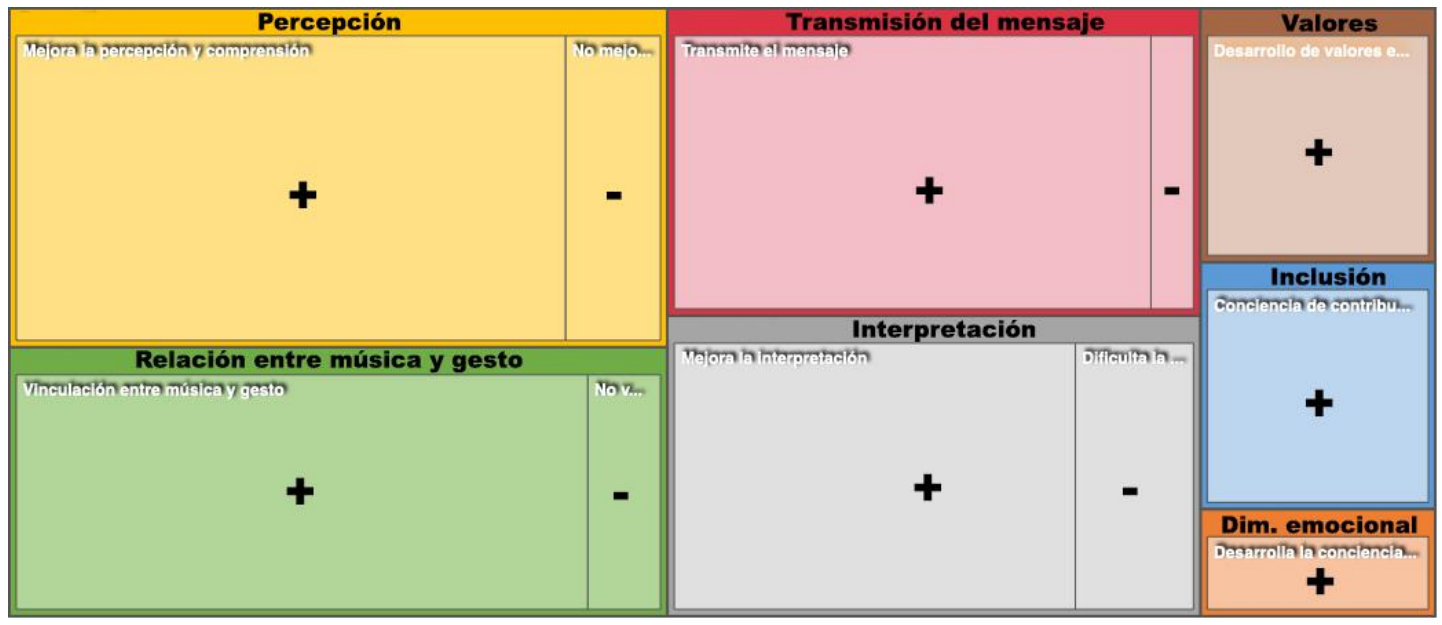

Figura 1. Mapa jerárquico correspondiente a las referencias de codificaciones de los instrumentos utilizados.

Fuente: Elaboración propia a partir de los datos obtenidos.

Sin embargo, al diseccionar la información, pueden encontrarse matices. Para facilitar la comprensión, la comparación y la visualización de los resultados, van a presentarse tres figuras correspondientes a la triangulación parcial de algunos resultados. Después de ilustrarlos jerárquicamente, se presentará el análisis individual de cada una de las figuras.

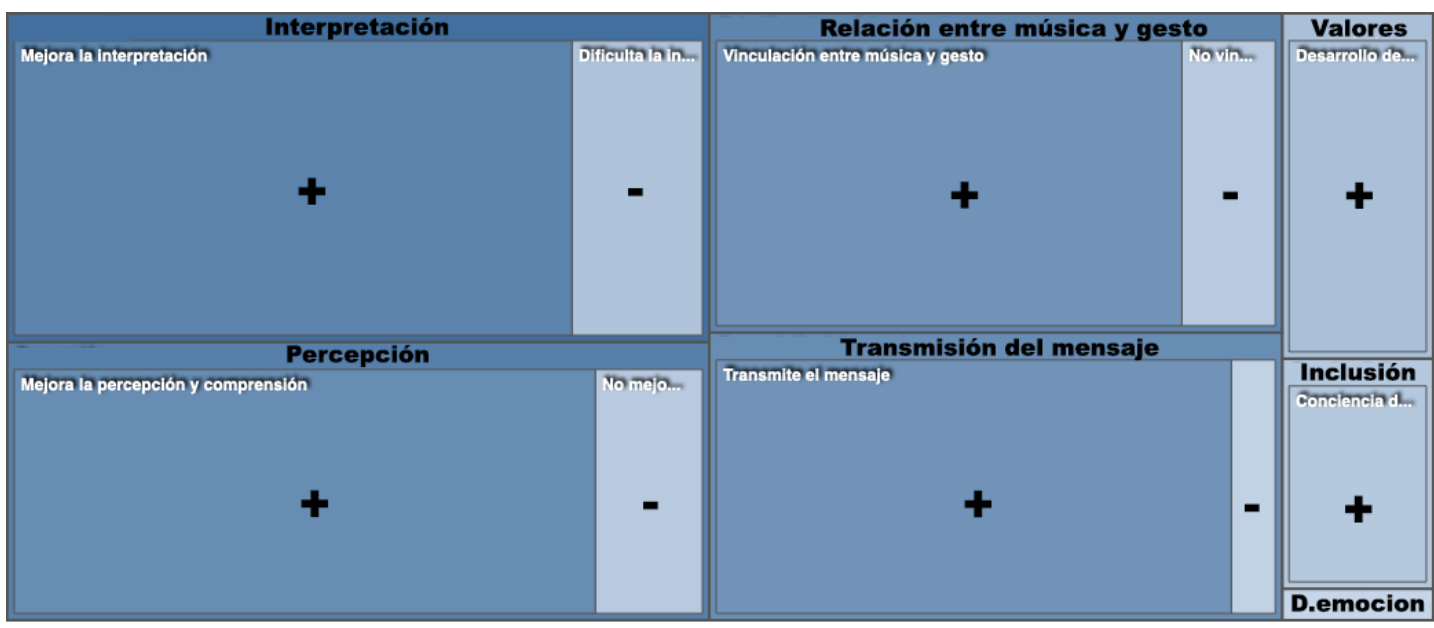

Figura 2. Mapa jerárquico correspondiente a la triangulación de las referencias de codificaciones de los Informantes Participantes, Ensayo reflejado en el cuaderno de campo y sesión de grupo de discusión. Fuente: Elaboración propia a partir de los datos obtenidos.

@ Borja Juan Morera, Icíar Nadal García y María Belén López Casanova. The content of this article is the sole responsibility of the authors. The Revista Electrónica de LEEME and Universitat de València are not liable for any legal actions that may arise involving the article's content. Revista Electrónica de LEEME - Lista Electrónica Europea de Música en la Educación-. http://ojs.uv.es/index/php/LEEME/index ISSN: 1575-9563. Editores: Universidad de Valencia y Jesús Tejada. Visibilidad de esta revista: SCOPUS, Emerging Sources Citation Index (Clarivate), EBSCO, CINDOC (CSIC), Citefactor, COPAC, Dialnet, DICE (CSIC), DOAJ, e-revistas (CSIC), EBSCO Premier, ERIH+, Gale Cengage Learning, IN-RECS, IRESIE, LATINDEX, MIAR, OCLC Worldcat, RESH, REDIB, RILM Core Journals, SUDOC, ULRICHS. Esta revista es de acceso libre mediante licencia Creative Commons 4.0 CC by. Política de archivado: etiqueta verde SHERPA-ROMEO. 


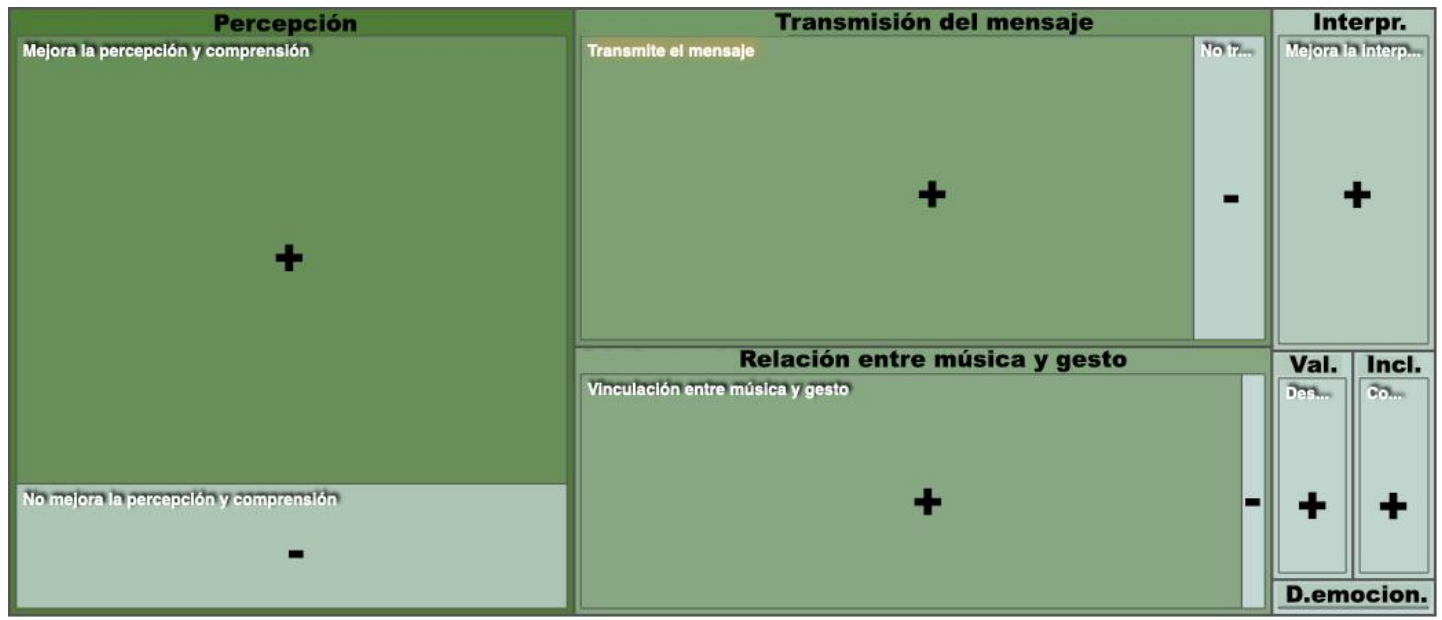

Figura 3. Mapa jerárquico correspondiente a la triangulación de las referencias de codificaciones de los Informantes Externos (oyentes).

Fuente: Elaboración propia a partir de los datos obtenidos.

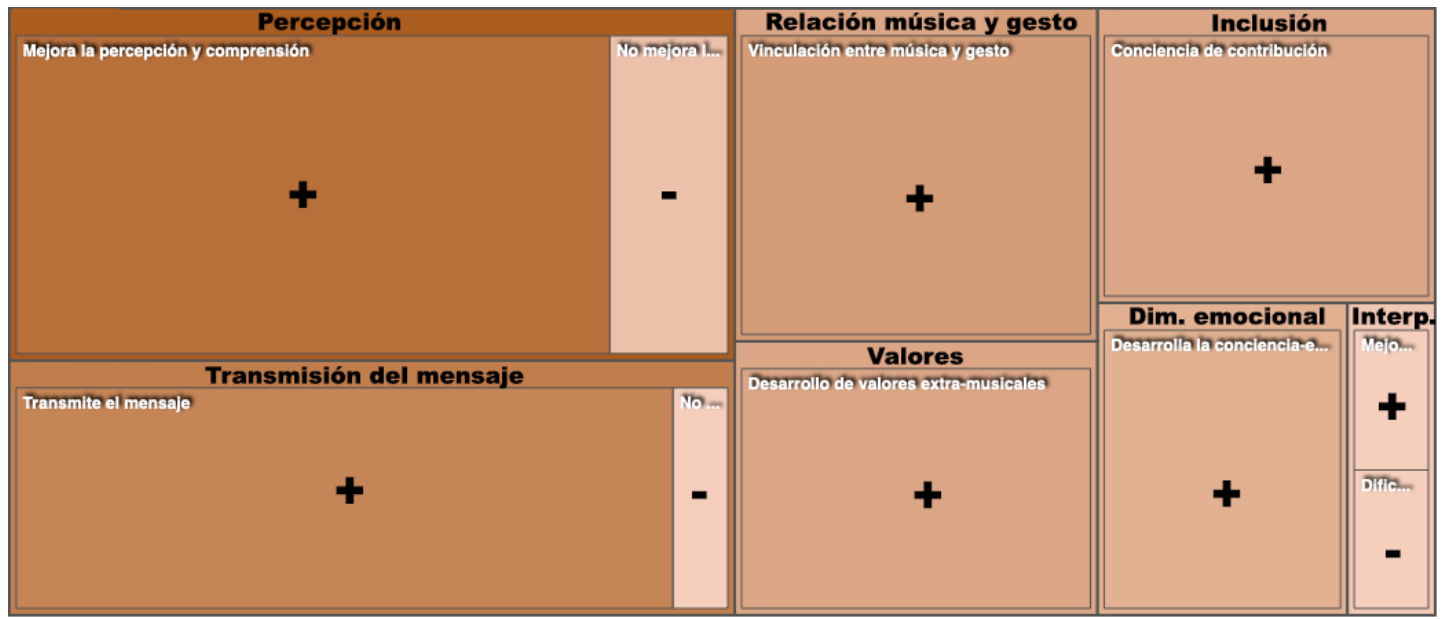

Figura 4. Mapa jerárquico correspondiente a la triangulación de las referencias de codificaciones de los Informantes Sordos y las experiencias registradas con la comunidad sorda.

Fuente: Elaboración propia a partir de los datos obtenidos.

Atendiendo a los datos obtenidos por medio de las entrevistas a los informadores participantes, así como triangulando las afirmaciones extraídas del grupo de discusión y la sesión de ensayo interna anotada en el cuaderno del investigador, se obtiene una jerarquía diferente a la global. Puede observarse, que al tratarse de "los intérpretes", las categorías correspondientes a la interpretación, su mejora o su dificultad, acompañada de lengua de signos, cobran mucha fuerza. Los cuatro bloques categoriales principales se mantienen como tal, con una representatividad y proporcionalidad que refuerza la hipótesis de que el signado de música a cuatro voces tiene un significado y utilidad reales para los intérpretes, oyentes o no.

@ Borja Juan Morera, Icíar Nadal García y María Belén López Casanova. The content of this article is the sole responsibility of the authors. The Revista Electrónica de LEEME and Universitat de València are not liable for any legal actions that may arise involving the article's content. Revista Electrónica de LEEME - Lista Electrónica Europea de Música en la Educación-. http://ojs.uv.es/index/php/LEEME/index ISSN: 1575-9563. Editores: Universidad de Valencia y Jesús Tejada. Visibilidad de esta revista: SCOPUS, Emerging Sources Citation Index (Clarivate), EBSCO, CINDOC (CSIC), Citefactor, COPAC, Dialnet, DICE (CSIC), DOAJ, e-revistas (CSIC), EBSCO Premier, ERIH+, Gale Cengage Learning, IN-RECS, IRESIE, LATINDEX, MIAR, OCLC Worldcat, RESH, REDIB, RILM Core Journals, SUDOC, ULRICHS. Esta revista es de acceso libre mediante licencia Creative Commons 4.0 CC by. Política de archivado: etiqueta verde SHERPA-ROMEO. 


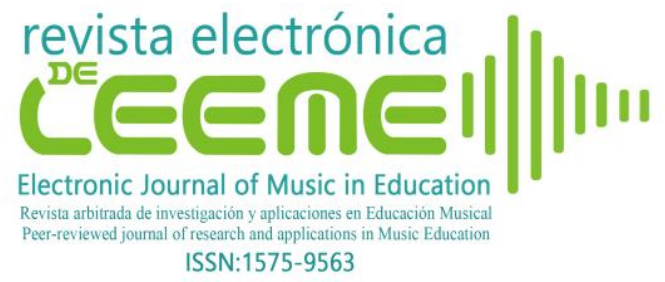

Si se comparan la figura 2 con las 3 y 4 , se observa que es la única donde las cuatro macro categorías aparecen relativamente similares en peso y relevancia. En el caso de la figura 3 , correspondiente a la información dada por los informantes externos, las categorías más significativas son las que centran su foco en la percepción y comprensión de la música signada, seguido de cerca por la transmisión del mensaje y la vinculación entre signos música. Las categorías referentes a la interpretación se ven desplazadas a un lugar más discreto.

En cuanto a la figura 4, perteneciente a la triangulación obtenida de la informante externa con diversidad funcional auditiva y las dos experiencias registradas con comunidad sorda, infantil y adulta, se detecta cómo la categoría de interpretación desaparece; sin embargo, la de percepción y transmisión del mensaje comparten protagonismo, seguidas de informaciones que hacen referencia a la relación entre la música y el signado. Es especialmente notable que, en el caso de la figura 4, las categorías referentes a la dimensión emocional, inclusiva y extramusical ganan un peso mucho mayor que en las dos figuras anteriores.

A nivel global, triangulando toda la información, y eliminando palabras irrelevantes o carentes de un significado concreto, se genera una nube de términos (Figura 5) con los 30 más referenciados en el total de las intervenciones o situaciones registradas.

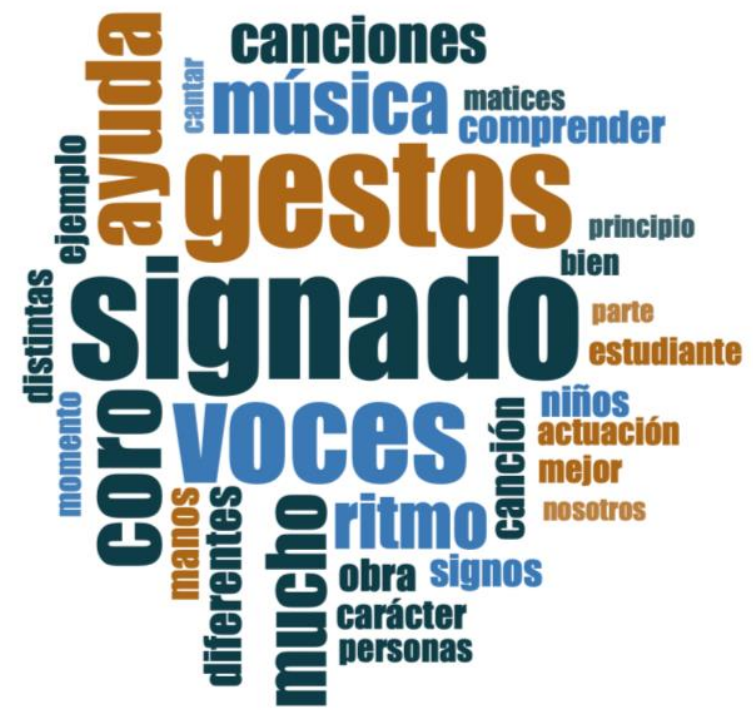

Figura 5. Nube de las 30 palabras más referenciadas en la totalidad de los datos analizados.

Fuente: Elaboración propia a partir de los datos obtenidos.

Todos los informantes participantes afirman que el signado supone una dificultad al principio, pero al aprenderlo, "sale solo" o, incluso, ayuda a la interpretación. Se destaca el valor expresivo del gesto, la comprensión de la música desde planos diferentes o la empatía hacia un público y compañeros diversos. No obstante, se desliga ligeramente de estas afirmaciones el I.P.4, cuyo perfil con Síndrome Asperger le supone una mayor dificultad para asociar el gesto y la música, entendiéndose como elementos distintos. Aunque, mientras, como

@ Borja Juan Morera, Icíar Nadal García y María Belén López Casanova. The content of this article is the sole responsibility of the authors. The Revista Electrónica de LEEME and Universitat de València are not liable for any legal actions that may arise involving the article's content. Revista Electrónica de LEEME - Lista Electrónica Europea de Música en la Educación-. http://ojs.uv.es/index/php/LEEME/index ISSN: 1575-9563. Editores: Universidad de Valencia y Jesús Tejada. Visibilidad de esta revista: SCOPUS, Emerging Sources Citation Index (Clarivate), EBSCO, CINDOC (CSIC), Citefactor, COPAC, Dialnet, DICE (CSIC), DOAJ, e-revistas (CSIC), EBSCO Premier, ERIH+, Gale Cengage Learning, IN-RECS, IRESIE, LATINDEX, MIAR, OCLC Worldcat, RESH, REDIB, RILM Core Journals, SUDOC, ULRICHS. Esta revista es de acceso libre mediante licencia Creative Commons 4.0 CC by. Política de archivado: etiqueta verde SHERPA-ROMEO. 
afirma que: "Yo creo que el signado con la voz son cosas muy distintas." también afirma "es más tranquila y haces los gestos de una manera más detallada, más lenta... Y quieras que no se transmite esa suavidad y tranquilidad".

Es interesante la profundidad con la que perciben la interpretación del coro Cantatutti aquellas personas que tienen conocimientos musicales o, aquellas que, al ser sordas, tienen dificultad para percibirla auditivamente (Figura 6).

I.P.3

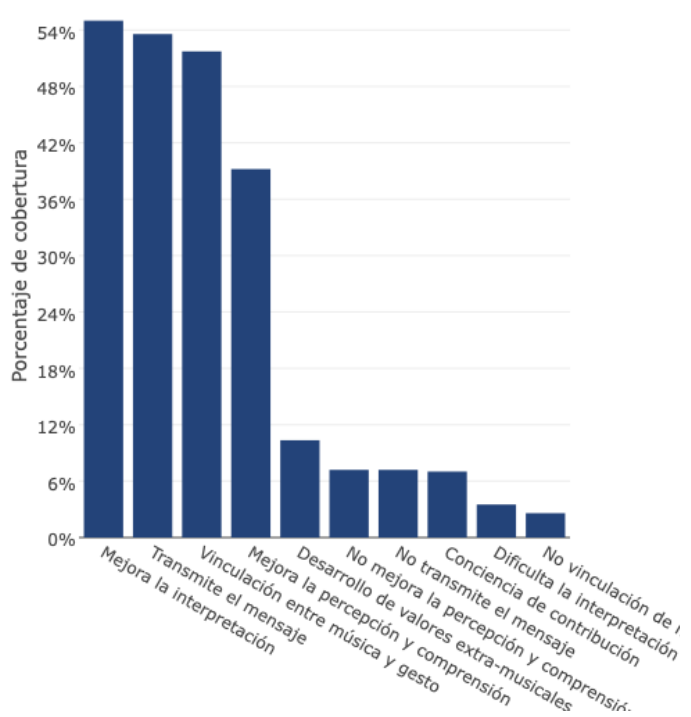

I.P.4

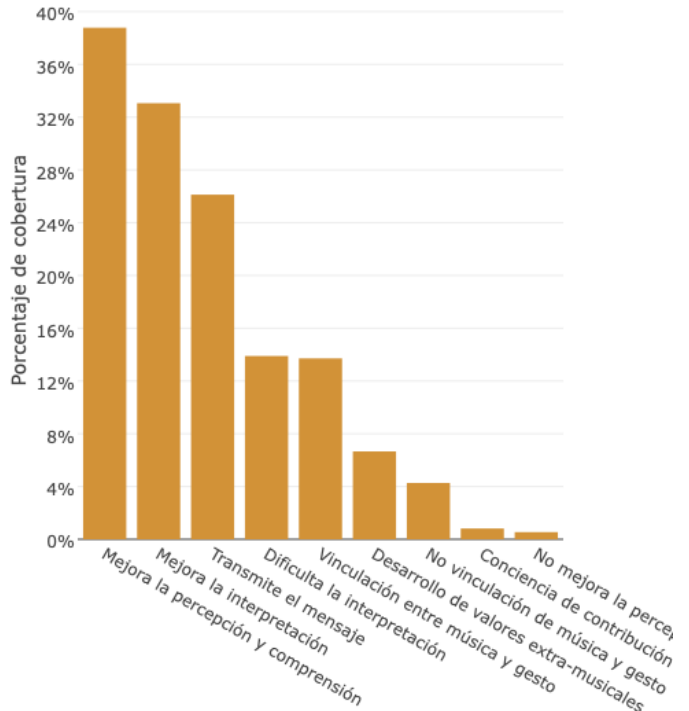

Figura 6. Comparación de los porcentajes de cobertura en las categorías entre el sujeto I.P.4 y otro de los restantes. Fuente: Elaboración propia a partir de los datos obtenidos.

Los matices y detalles que aportan enriquecen la investigación. Por ejemplo:

I.E.3: "Puedo apreciar como el gesto cambia la intensidad, la amplitud, la velocidad, en función de la obra que están cantando. Pienso que esta es una parte muy importante que da sentido al uso del signado en el coro y que se debe seguir avanzando en este terreno."

"Cuando todo el coro realiza los mismos gestos aprecio que cantan al unísono y cuando cada cuerda empieza a hacer sus gestos por separado, empieza un juego de movimientos por bloques que muestra corporalmente la polifonía."

I.E.4: "Yo como persona sorda me parece... depende de las personas sordas, si son postlocutivas, o sea que han escuchado antes la música y luego han perdido la audición, sí que puede ayudar, pero yo que no tengo audición de nacimiento no puedo, escucho la música ... pero no noto las diferencias si es rock, si es rap, si es clásica, esto no lo noto yo."

Por último, es reseñable que los aspectos "más musicales" o ligados comúnmente a la "audición" son citados por la comunidad sorda en numerosas ocasiones, como así reflejan los cuadros jerárquicos por categorías que analizados previamente (Figura 4). Se exponen como

@ Borja Juan Morera, Icíar Nadal García y María Belén López Casanova. The content of this article is the sole responsibility of the authors. The Revista Electrónica de LEEME and Universitat de València are not liable for any legal actions that may arise involving the article's content. Revista Electrónica de LEEME - Lista Electrónica Europea de Música en la Educación-. http://ojs.uv.es/index/php/LEEME/index ISSN: 1575-9563. Editores: Universidad de Valencia y Jesús Tejada. Visibilidad de esta revista: SCOPUS, Emerging Sources Citation Index (Clarivate), EBSCO, CINDOC (CSIC), Citefactor, COPAC, Dialnet, DICE (CSIC), DOAJ, e-revistas (CSIC), EBSCO Premier, ERIH+, Gale Cengage Learning, IN-RECS, IRESIE, LATINDEX, MIAR, OCLC Worldcat, RESH, REDIB, RILM Core Journals, SUDOC, ULRICHS. Esta revista es de acceso libre mediante licencia Creative Commons 4.0 CC by. Política de archivado: etiqueta verde SHERPA-ROMEO. 
ejemplo algunas anotaciones del cuaderno de campo referente a la experiencia con los miembros de ASZA en 2018:

\footnotetext{
- Ellos dicen que sí que les ha llegado nuestra interpretación y que para ellos es muy importante la contextualización de la obra.

- Les ha sorprendido que distintos grupos de personas (voces), signen distintas cosas. Les ha parecido divertido, dinámico y que aportaba entretenimiento a la historia de la que "hablaba" la canción.

- Les ha impresionado el contraste entre los signados enérgicos y rítmicos frente a los pausados, largos y dulces, eso les ha transmitido distintas emociones e intensidades.

- Algo que también dicen haber sentido es la alegría que transmite el coro.
}

\section{Discusión y conclusiones}

La mayoría de las investigaciones y estudios encontrados sobre interpretación de música en lengua de signos pueden localizarse en autores estadounidenses como Begue y Cripps (2018); Buchholz, (2018); Cripps, Rosenblum, y Small (2016); Cripps y Lyonblum (2017); Cripps (2018); Listman, Loeffler y Timm (2018); Pirone (2018); Silvestri, Ehrenberg, Dick y Shim (2018). Para abordar este tipo de estudios hay que basarse, principalmente, en documentos videográficos que los diferentes autores analizan para extraer sus conclusiones.

Puede constatarse que, en la actualidad, con el desarrollo de vídeos de música signada, y su aparición en las redes sociales, la interpretación y el signado de música y canciones tiene una importante difusión y repercusión entre la comunidad sorda y oyente. Begue y Cripps (2018) comparten y analizan el proceso de creación de vídeos musicales en lengua de signos y reflexionan sobre la estética visual del ritmo y las posibilidades de mejora de las técnicas utilizadas. Se extiende cada vez más la creencia de que los sordos son capaces de disfrutar y de sentir la música. No obstante, y aunque la música no aparece en eventos de la cultura sorda, la mayoría de los autores citados, animan a que se extiendan y amplíen estas prácticas. En este estudio, se corrobora que el signado de canciones beneficia tanto a la comunidad sorda como a la oyente, ya que acerca la música desde la perspectiva de la representación visual, a través del movimiento rítmico, la expresión facial y corporal y, la lengua de signos. Estas prácticas suponen la vivencia y asimilación de conceptos musicales como, por ejemplo, la textura musical, en el caso de la polifonía coral. Los resultados obtenidos coinciden con Maler (2013), cuando afirma que las canciones signadas comprenden cuatro formas de expresión: música, letra, lengua de signos (LS) y otros gestos independientes de la LS (baile, balanceo, ritmo, etc.).

La interpretación de canciones en lengua de signos carece de sentido si no se tiene en cuenta el "factor expresivo" defendido por Silvestri et al. (2018). Además, debe considerarse, tal como apunta Val (2015), que la respiración también forma parte de la comunicación.

A través del estudio de caso realizado con el Coro Cantatutti, constatamos que el signado a voces, dota de significado al discurso y la interpretación musical y contribuye en

@ Borja Juan Morera, Icíar Nadal García y María Belén López Casanova. The content of this article is the sole responsibility of the authors. The Revista Electrónica de LEEME and Universitat de València are not liable for any legal actions that may arise involving the article's content. Revista Electrónica de LEEME - Lista Electrónica Europea de Música en la Educación-. http://ojs.uv.es/index/php/LEEME/index ISSN: 1575-9563. Editores: Universidad de Valencia y Jesús Tejada. Visibilidad de esta revista: SCOPUS, Emerging Sources Citation Index (Clarivate), EBSCO, CINDOC (CSIC), Citefactor, COPAC, Dialnet, DICE (CSIC), DOAJ, e-revistas (CSIC), EBSCO Premier, ERIH+, Gale Cengage Learning, IN-RECS, IRESIE, LATINDEX, MIAR, OCLC Worldcat, RESH, REDIB, RILM Core Journals, SUDOC, ULRICHS. Esta revista es de acceso libre mediante licencia Creative Commons 4.0 CC by. Política de archivado: etiqueta verde SHERPA-ROMEO. 
aspectos técnicos del canto como pueden ser la correcta emisión, respiración, proyección o fraseo, dado que, la musicalidad del gesto acompaña la intención melódico-rítmica de la música, así como el carácter o los distintos matices.

El trabajo realizado permite concluir que el signado de obras polifónicas interpretadas por un coro, acerca la música a personas con y sin discapacidad auditiva. Se refuerza el concepto de polifonía de forma visual, donde se aprecia el juego dialéctico de las voces. De manera que, la interpretación musical de la polifonía en lengua de signos favorece la inclusión y amplía el acceso a la cultura de las personas sordas.

\section{Referencias}

Arnal, J., Del Rincón, D. y Latorre, A. (1992). Investigación educativa. Metodologías de investigación educativa. Barcelona: Labor.

Bahan, B. (2006). Face-to-face tradition in the American Deaf Community. En H-D. Baumen, J.L. Nelson y H. Ros (Ed.), Signing the body poetic (pp.21-50). London: University of California Press.

Begue, J. y Cripps, J. (2018). The Artwork of Video Editing in Signed Music. Journal of American Sign Languages \& Literatures. Recuperado de: http://journalofasl.com/wpcontent/uploads/sites/8/2018/08/the-artwork-of-video-editing-in-signed-music.pdf

Buchholz, N. (2018). Seeing Music? An Inquiry into the Place of Music in Deaf Culture. Journal of American Sign Languages \& Literatures. Recuperado de: http://journalofasl.com/wp-content/uploads/sites/8/2018/06/buchholz.pdf

Cohen, L. y Manion, L. (1990). Métodos de investigación educativa. Madrid: La Muralla.

Cook, N. (2017). Music, performance, meaning. Londres: Routledge.

Cripps, J.H., Rosenblum, E. y Small, A. (2016). Music, Signed. En G. Gertz y P. Boudreault (Ed.), The SAGE Deaf Studies Encyclopedia (pp.703-706). Thousand Oaks: SAGE Publications.

Cripps, J.H. y Lyonblum, E. (2017). Understanding the use of signed language for making music. SASLJ Journal, 1(1), 78-95. Recuperado de: $\underline{\text { http://tigerprints.clemson.edu/cgi/viewcontent.cgi?article=1000\&context=saslj }}$

Cripps, J.H. (2018). Ethnomusicology \& Signed Music: A Breakthrough. Journal of American Sign Languages \& Literatures. Recuperado de: http://journalofasl.com/wpcontent/uploads/sites/8/2018/08/ethnomusicology_cripps.pdf

@ Borja Juan Morera, Icíar Nadal García y María Belén López Casanova. The content of this article is the sole responsibility of the authors. The Revista Electrónica de LEEME and Universitat de València are not liable for any legal actions that may arise involving the article's content. Revista Electrónica de LEEME - Lista Electrónica Europea de Música en la Educación-. http://ojs.uv.es/index/php/LEEME/index ISSN: 1575-9563. Editores: Universidad de Valencia y Jesús Tejada. Visibilidad de esta revista: SCOPUS, Emerging Sources Citation Index (Clarivate), EBSCO, CINDOC (CSIC), Citefactor, COPAC, Dialnet, DICE (CSIC), DOAJ, e-revistas (CSIC), EBSCO Premier, ERIH+, Gale Cengage Learning, IN-RECS, IRESIE, LATINDEX, MIAR, OCLC Worldcat, RESH, REDIB, RILM Core Journals, SUDOC, ULRICHS. Esta revista es de acceso libre mediante licencia Creative Commons 4.0 CC by. Política de archivado: etiqueta verde SHERPA-ROMEO. 
Ferraro, S. (2018). Lengua de signos. Sistema bimodal y Baby signs. Recuperado de: https://www.comunikatbabysigns.com/2018/10/12/lengua-de-signos-sistema-bimodaly-baby-signs/

García, A. (2016, 6 de septiembre). Rozalen \& Beatriz Romero. Música que se escucha con los ojos. El País Semanal. Recuperado de https://elpais.com/elpais/2016/09/06/eps/1473113144_147311.html

Imbernón, F. (2002). La investigación educativa como herramienta de formación del profesorado. Reflexión y experiencias de investigación educativa. Barcelona: Graó.

Jones, J. (2017). How ingenious sign language interpreters are bringing music to life for the deaf: visualizing the sound of rhythm, harmony \& melody. Recuperado de: http://www.openculture.com/2017/04/how-ingenious-sign-language-interpreters-arebringing-music-to-life-for-the-deaf.html

Kaneko M. (2011). Alliteration in Sign Language Poetry. En J. Roper (Ed.), Alliteration in Culture (pp. 231-246). London: Palgrave Macmillan.

Krueger, R. (1991). El grupo de discusión. Guía práctica para la investigación aplicada. Madrid: Pirámide.

Listman, J. Loeffler, S.C. y Timm, R.L. (2018). Deaf Musicality and Unearthing the Translation Process. Journal of American Sign Languages \& Literatures. Recuperado de: http://journnnalofasl.com/wp-content/uploads/sites/8/2018/08/deaf-musicality.pdf

Maler, A. (2013). Songs for Hands: Analyzing Interactions of Sign Language and Music. Journal of the Society for Music Theory, 19(1). Recuperado de: http://mtosmt.org/issues/mto.13.19.1/mto.13.19.1.maler.html

Peñalba A., Moriyón, C. y Luque, S. (2018). Más que sonido: interpretación de música instrumental en lengua de signos para las personas sordas. Tabanque. Revista Pedagógica, 31, 94-107. doi: 10.24197/trp.31.2018.94-107

Pirone, J. (2018). Does Music Have a Place in ASL Pedagogy? Journal of American Sign Languages \& Literatures. Recuperado de: http://journalofasl.com/wpcontent/uploads/sites/8/2018/06/pirone.pdf

Ruiz Marull, D. (2017, 14 de julio). Los intérpretes en lengua de signos, las nuevas estrellas de los conciertos. La vanguardia. Recuperado de https://www.lavanguardia.com/cultura/20170714/424092363556/interprete-signossordos-conciertos-holly-maniatty-waka-flocka-snoop-dogg.html

@ Borja Juan Morera, Icíar Nadal García y María Belén López Casanova. The content of this article is the sole responsibility of the authors. The Revista Electrónica de LEEME and Universitat de València are not liable for any legal actions that may arise involving the article's content. Revista Electrónica de LEEME - Lista Electrónica Europea de Música en la Educación-. http://ojs.uv.es/index/php/LEEME/index ISSN: 1575-9563. Editores: Universidad de Valencia y Jesús Tejada. Visibilidad de esta revista: SCOPUS, Emerging Sources Citation Index (Clarivate), EBSCO, CINDOC (CSIC), Citefactor, COPAC, Dialnet, DICE (CSIC), DOAJ, e-revistas (CSIC), EBSCO Premier, ERIH+, Gale Cengage Learning, IN-RECS, IRESIE, LATINDEX, MIAR, OCLC Worldcat, RESH, REDIB, RILM Core Journals, SUDOC, ULRICHS. Esta revista es de acceso libre mediante licencia Creative Commons 4.0 CC by. Política de archivado: etiqueta verde SHERPA-ROMEO. 
Ruiz Olabuénaga, J.L. (1999). Metodología de investigación cualitativa. Bilbao: Universidad de Deusto.

Schlesinger, J.S. (1978). Nonverbal Communication: Information and Application for Counselors. Journal of Counceling \& Development, 57(4), 183-187. doi: 10.1002/j.2164-4918.1978.tb05140.x

Serna, E.M. y Piñero P. (2018). La interpretación de canciones en lengua de signos española: problemas traductológicos. En M.L. Esteban (Coord.), Actas del Congreso CNLSE de la lengua de signos Española (pp.65-75). Madrid: Real Patronato sobre Discapacidad.

Silvestri, J., Ehrenberg, H., Dick, L. y Shim, P. (2018). Universal Design for Music: Exploring the Intersection of Deaf Education and Music Education. Journal of American Sign Languages \& Literatures. Recuperado de: http://journalofasl.com/wpcontent/uploads/sites/8/2018/06/udl.pdf

Straus, J. N. (2011). Extraordinary Measures: Disability in Music. New York: Oxford University Press.

Thompson R. H., Cotnoir-Bichelman N. M., McKerchar P.M., Tate T. L., Dancho K. A. (2007). Enhancing early communication through infant sign training. Journal of Applied Behavior Analysis, 40(1),15-23. doi: 10.1901/jaba.2007.23-06

Val, A. (2015). The process of nonverbal communication between choir and conductor. Revista Electrónica de LEEME, 36, 49-70. Recuperado de: http://ojs.uv.es/index.php/LEEME/article/view/9873/9292

Valdés, C. (2013). La lengua de signos y la comunicación bimodal. Recuperado de http://valdescarmen.blogspot.com/2013/07/la-lengua-de-signos-y-la-comunicacion.html

Valle, M. (2008). El cantautor Tontxu habla de la irrupción de la LSE en la Música. Faro del Silencio. Revista de la Confederación Estatal de Personas Sordas (CNSE), 224, 20-23. Recuperado de: http://www.cnse.es/uploaded/publicaciones/224.pdf

@ Borja Juan Morera, Icíar Nadal García y María Belén López Casanova. The content of this article is the sole responsibility of the authors. The Revista Electrónica de LEEME and Universitat de València are not liable for any legal actions that may arise involving the article's content. Revista Electrónica de LEEME - Lista Electrónica Europea de Música en la Educación-. http://ojs.uv.es/index/php/LEEME/index ISSN: 1575-9563. Editores: Universidad de Valencia y Jesús Tejada. Visibilidad de esta revista: SCOPUS, Emerging Sources Citation Index (Clarivate), EBSCO, CINDOC (CSIC), Citefactor, COPAC, Dialnet, DICE (CSIC), DOAJ, e-revistas (CSIC), EBSCO Premier, ERIH+, Gale Cengage Learning, IN-RECS, IRESIE, LATINDEX, MIAR, OCLC Worldcat, RESH, REDIB, RILM Core Journals, SUDOC, ULRICHS. Esta revista es de acceso libre mediante licencia Creative Commons 4.0 CC by. Política de archivado: etiqueta verde SHERPA-ROMEO. 